\title{
Ethnographies of Touch and Touching Ethnographies: Some Prospects for Touch in Anthropological Enquiries
}

\author{
By Rosemary Blake (University of Cape Town)
}

The question of what constitutes data in anthropology is on-going and contested. In particular, challenges to dualistic assumptions about the mind and body as separate have opened up new spaces in which we can explore what it means to be engaged or embedded in the field and how we can employ our own subjectivity and experiences in the field as tools for research. In this paper, I extrapolate these assertions, looking at the role that touch, as a social practice both observed and participated in during fieldwork, played in shaping the way I conducted research as well as the subsequent theorisations that emerged from this research. I consider how meanings and messages can be relayed through the skin, and by the skin, in a dialogue of embodied knowledge between the researcher, the field and the research participants.

\section{Introduction}

In 2007 I engaged in a brief stint of fieldwork in an oncology ward at a South African provincial children's hospital. The relationships that I formed with the research participants during this fieldwork, primarily the children receiving in-patient treatment, were shaped, and to some extent premised, on particular interactions and modes of touch. This experience led me to consider the ways in which touch, as both a social practice and a lived experience, might be theorised and employed in anthropological enquiries. I begin this paper by looking at the changes that have occurred, since the 1970's, in the ways that anthropologists think about and locate the body. I use this as a platform to consider the implications that new ways of seeing the body have for the manners ethnographies are conducted and written-up. Looking at some of the ways in which sensory modalities have been used in anthropological enterprises, I then consider how touch, a sense which - I argue - has been largely neglected in anthropological enquiries, might be thought about and employed during research.

\section{The Mindful Body}

Beginning in the 1970s, and gaining in momentum ever since, a notion of the body as socially, rather than naturally, constructed has become a central focus for anthropology and medical anthropology in particular. Underpinning this increasing concern for the body as a site and subject of research is the overt endeavour to challenge dualistic assumptions which regard 'the mind' and 'the body' as separate entities; instead, a view of the body as 'lived' and 'mindful' has come to the fore (see Farquhar \& Lock 2007 and Scheper-Hughes \& Lock 1987).

Drawing on phenomenological philosophy, a movement stretching back to the mid1800 s which considers - without opposing - the relationship between subjectivity, objectivity, experience, materiality and perception, anthropologists began to challenge the polarised dichotomies of mind/body and subject/object by considering the ways in which 
the body lives in and is 'lived through' the world. In this effort, the work of MerleauPonty has proved a guiding light. In his magnum opus The Phenomenology of Perception, Merleau-Ponty argued that it is perception - our sensory experience of the world - which underpins our understanding and interaction with the world. In his work, Merleau-Ponty '...[sought] to restore to perception its world-making activity and to see the world as an intersection of the various experiences of the embodied, intentional self' (Farquhar and Lock 2007). This idea has been used by anthropologists to validate the use and exploration of sensory modalities in ethnographic research (see Stoller 1989).

Thus, intersecting these ideas about the way in which 'the body' is constituted as a theoretical site in anthropology are challenges to the positivist approach that the 'harder' sciences adopt. Efforts towards a more experiential or phenomenological approach to understanding the body can be seen to dovetail with ideas about the unavoidable subjectivity of the social researcher and the unattainability (or nonsensicality) of objective and complete understandings within social research (Csordas 1994; Okely 2007).

The view of the researcher as necessarily subjective has led to the practice of reflexive extrapolations within ethnographic writing becoming almost an ethical requirement (Clifford and Marcus 1986) whereby anthropologists write against the representation of the anthropologist as all-knowing and unbiased. Formerly taken-for-granted notions of knowledge have come under scrutiny with anthropologists such as Michael Jackson using a focus on experience to challenge the notions of 'determinant systems of knowledge' (Jackson 1995: 160) espoused in positivist disciplines and sometimes implicit in the anthropological enterprise. Rather, it is argued, we reflect on our embodied experiences in and of the field and how these shape and produce our knowledge in and of the field whilst simultaneously acknowledging that 'words alone can never do justice to experience' (Jackson 1995: 160). The embodied nature of knowledge is being recognised and the movement towards reflexive accounts is as much about rethinking what constitutes valid data as it is about challenging former assumptions about ethnographic authority.

On this note, a connection can be drawn between a dualistic notion of the body in which one is able to imagine a cool, observing mind, detached from the hot, emotionally swayed body and the bias that has been historically and persistently shown towards the visual in ethnographic accounts and in the presentation of ethnographic data (Rasmussen 2006). Yet, as I attempted to show above, the notion of a 'mindful body' coupled with an emphasis on the necessary subjectivity of ethnographic accounts can lead to an appreciation of the anthropological researcher as a socially embedded and embodied being engaged in rich emotional and sensual experiences in the field. In the introduction to Beyond the Body Proper (2007), Margaret Lock and Judith Farquhar put it thus:

'... as anthropology has moved beyond the body proper it has opened up a new stratum of social existence, one that offers a broad terrain for research between the impossible poles of a Cartesian social science. This is the domain of neither a cultural mind nor a biological body, but of a lively carnality suffused with words, images, senses, desires, and powers' (2007: 15). 
Similarly, in her piece titled Fieldwork Embodied, Judith Okely (2007) asserts that participation (that other, often unelaborated, side to participant observation) 'involves bodily engagement' (2007: 65). Hence, the researcher has emerged in recent years as one who is not just socially and intellectually involved in the processes and interactions of research but also a kind of subjective sensual explorer who engages bodily in and with the field. Below I detail two of the ways in which anthropologists have used their bodies, specifically their sensory experiences, in their ethnographic efforts.

Pioneering the way in sensory anthropology, Paul Stoller, in his The Taste of Ethnographic Things (1989), saw the sensory experiences of research as not simply a means by which one might add vividness and richness to ethnographic accounts but as a way to render 'our accounts of others more faithful to the realities of the field - accounts which will then be more, rather than less, scientific' (1989: 9 emphasis in original). This, then, presents an interesting contrast with Jackson's assertion that a focus on experience can be used to challenge the authority of a scientific notion of whole and objective knowledge yet the two authors' views converge on their recognition of experience as a significant gap needing redress in ethnographic representations (Jackson 1995). In At Home in the World (1995), Jackson explicitly attempts to develop a way of writing that 'would be consonant with lived experience, in all its variety and ambiguity' by providing vivid first-person accounts. Sensory anthropology emerges as a way in which one can better represent, and possibly better remain aware of, the 'being-ness' of 'being in the field' regardless of whether one sees this as a route to increased clarity or greater ambiguity.

Another approach to the senses in ethnography can be found in the work of those anthropologists who have used their senses to explore and challenge notions of sensory experience itself. One example here would be Judith Farquhar's examination of the role that taste or flavour plays in some forms of Chinese herbal medicine (2002). By examining how one of the experiential qualities of Chinese herbal medicine, taste, is understood by users to be an integral property of medicinal effect, Farquhar challenges 'the dualistic categories of body and mind, emotion and cognition, experience and action, that have informed much Euro-American social science' (Farquhar and Lock 2007: 245). Another example of this kind of challenge can be found in a fascinating piece by Kathryn Geurts who explores 'a domain of experience' among Anlo-Ewe speaking people of south-eastern Ghana articulated in the word seselelame (which she translates as feel-feelat-flesh-inside). In addition to language analysis, Geurts embarks upon a kind of sensory analysis in which she explores the sensations she experienced when she accidentally drove over a rock which was believed to be a kind of 'spiritual guardian of thresholds' by those she was living with (2003: 195). By analysing the subsequent significances or modes of interpretation that she accorded to the sensations she experienced during this event and how these differed from those communicated by others, she demonstrates the rigidity of the 'traditional models for how we think about how we perceive' (2003: 196).

However, one source of sensory perception which seems to have received surprisingly little attention from either of these movements is that of touch. With a few notable exceptions, relatively little has been written on the way in which the skin, as a site of tactile sensation and social practice, comes into play in the research endeavour or in research enquiries. Below I describe the conditions under which I first came to think about touch and the subsequent enquiries that this led to. 


\section{The Role of Touch in the Oncology Ward at a Children's Hospital}

I first came to consider touch as an important anthropological consideration whilst conducting research in the oncology ward of a children's hospital. I was in the ward hoping to uncover children's experiences of cancer whilst receiving in-patient treatment chemotherapy - and I had imagined that I would be able to do this by collecting and analysing their 'illness narratives' (see Kleinman 1988). Instead, however, I was forced to reformulate this approach in the face of the children's resistance towards presenting their experiences in the manner I was trying to elicit. Instead of explanations about 'what cancer does in the body' and 'how it makes me feel' I was given clear and assertive narratives about how cancer treatments were disrupting their plans, relationships and appearance as well as descriptions of their hopes and struggles in moving beyond the inscription of sick. Skin emerged as an interesting indicator of this inscription. Hair loss meant that the children had an 'excess' of uncovered skin which immediately and dramatically inscribed them as sick and their skin was a surface regularly transgressed in the medical efforts to monitor and control the illness. In the children's descriptions the frequent and painful transgressions of their skin by needles and drips seemed to mirror the painful disruptions which the cancer diagnosis and its subsequent treatments caused to their school and home lives. However, not all instances of contact in the hospital were painful. Equally apparent was the way in which touch was used by the children as a source of comfort and by the adults as a means to convey care and comfort. The children were acutely aware of the pain that could be and was inflicted on them at the hands of another but they were equally aware of the efficacy of touch for imparting relief. When injections were being administered, hands were often held and when pain was ongoing and vague, heads were stroked or, if the child was small enough, entire bodies cuddled and held. It was not just the adults who instigated these comforting touches; they were emphatically requested by the children, even of relative strangers (such as me). Moreover, in my discussions with the children over the benefits of these touches many asserted that they provided not just comfort but actual pain alleviation - particularly when given by someone close to the child, such as a mother.

In hindsight it does not seem surprising that I would have encountered this in such a setting, but at the time I found it striking. I was particularly struck by the large role that touch came to play in my own interactions with the children and how this shaped my research. I had not encountered descriptions of touch in any of my readings and subsequent searches revealed that this was, in fact, a neglected area within anthropology. Below, I discuss three ideas I have about the ways in which anthropologists might think about touch. Drawing on the literature which I was able to find explicitly discussing touch, I consider, in the first section, touch as a dynamic and significant social practice worthy of exploration in anthropological endeavours. The second and third ideas relate to the way that the researcher's body can be consciously employed in the field; firstly as one who touches and secondly as one who is touched. These ways of thinking about touch intersect and though I attempt to discuss each separately in the following sections, I hope that the ways in which they overlap and fold into each other remain apparent.

\section{Touch as Social Practice}

My experience in the oncology ward led me on a search for literature on the subject of touch within anthropology. This search yielded little, with the notable exceptions of Susan Rasmussen's Those who Touch: Taureg Medicine Women in Anthropological Perspective (2006) and Constance Classen's Book of Touch (2005). 
In Those who Touch (Rasmussen 2006), an account is given of the role that touch plays in diagnoses given by Taureg medicine women. Here, in addition to observing how healing practices of touch are employed, it is argued that touch has been neglected within anthropology by contending that anthropologists typically exhibit a bias towards the visual in their ethnographic accounts. 'With few exceptions,' she asserts, 'unspoken elements in discourse tend to be trivialised or ignored' (Rasmussen 2006:59). Rasmussen maintains that touch is an important element of human communication and interaction which is due careful attention. In the case studies she presents, Rasmussen suggests that Taureg healers will have typically centred their thoughts to the sensitive reception, through their hands, of non-verbal messages and energy (ibid.). The messages that touch conveys can be, in her opinion, 'either conscious and purposeful or unconscious, with unintended but powerful consequences read differently by the receiver' (ibid.).

The Book of Touch (Classen 2005) comprises an assemblage of texts concerned, in a variety of ways, with how touch can be seen as a significant social practice. The pieces are short (usually just two or three pages long) and are typically not written by anthropologists. The book can be considered an anthropological text only by virtue of its editor and main contributor, Constance Classen, who attempts to present and relate the articles together in a manner that, it is hoped, will entice anthropologists to think anew about the significance of touch in social life.

As in Rasmussen's Those who Touch (2006) one of the foundational arguments being presented in The Book of Touch (2005) is that touch, as a social product, has been largely neglected in anthropology and academia in general. Moreover, further synthesis can be seen between Classen and Rasmussen's argument as Classen too explains this lack with reference to a bias towards the visual:

'Rather than grasping an issue, academics shed light on it... the use of such visual metaphors for the pursuit of knowledge discourages an active involvement with the subject matter and promotes a sciencebased model of detached observation... visual metaphors of cognition not only distance the thinker from the subject of thought - they also mask the tensions that touch-based terms indicate are involved in the intellectual processes. Knowledge is presented as readily apparent - all one has to do is look' (Classen 2005:5).

Classen goes beyond Rasmussen in the attention she gives to the question of how touch might actually be explored, writing that, "we enter a largely unfamiliar terrain when we ask what histories, what politics, what revelations of touch have animated social life? How do we communicate through touch? What are the cultural dimensions of pleasure and pain?' (2005: 2). The book has nine parts and each section 'centres on a basic quality, or function, of touch' (2005: 3). These functions and qualities include 'contact', pleasure and pain, gendered touch (specifically male bonding and women's touch), tactile therapies and control. The pieces presented under these headings come out of a variety of disciplines, and many present a historical view of how particular practices of touch have changed over time and across space. The ways in which Classen relates them are creative, if sometimes confusing. Under the section 'contact' there is a piece exploring the political implication of tactile metaphors such as burning and binding which proliferate in American religious and political discourses; there is a piece by Ruth Finnegan exploring 
the ways in which touch is used to express and create particular kinds of relationships (and the power dynamics inherent within them); and there is a piece exploring changes in the advice that professionals have given mothers regarding how they handle their children. It could be argued that this flexible mode of association reflects the flexibility of touch as a theoretical subject. Touch is a diffuse experience; of all our sensory organs, the skin is the largest. It occupies and traverses space and the skin's sensitivity to touch varies greatly across its surface. Moreover, touch involves pressure sensations as well as nerve sensations. Feeling is complex and often ambiguous and the range of perspectives offered in Classen's book reflects this well.

Given my observations in the ward on the efficacy of touch for pain alleviation, I was particularly interested in the section on 'tactile therapies'. In an examination of biblical verses detailing accounts of healing through the 'laying of hands' and an exploration of historical texts on the role that 'healing hands' played in validating $16^{\text {th }}$ and $17^{\text {th }}$ century entitlements to the throne in England, Classen argues that in 'the West', 'the notion of touch having the power to heal has a long history' (2005: 347). She then goes on to argue that while the idea of 'healing hands' might have largely lost its connection to supernatural forces in contemporary Western thought, the idea still persists, as evidenced by current Western biomedical practices such as physiotherapy. Moving her focus to socalled 'non-Western' healthcare systems, Classen argues that here too is much evidence of both historical and persistent usages of touch as healing practise, listing acupuncture, yogic exercise and Ayurvedic massage as just three examples. Returning to touch in Western medicine, Classen then suggests that touch can play a major role in the creation and maintenance of power relations between doctor and patient. She explains that the routine of the modern physical examination - testing reflexes, taking the blood pressure and so on - is not only a means of ascertaining the patient's state of health but also a performance in which the physician enacts his identity through a set of established procedures and confirms his right, 'above all, to touch and penetrate the body' (Porter 1993: 179, cited in Classen 2005: 349). Classen completes the piece by suggesting that much of the healing efficacy of touch has roots in the expressions of love and care that touch can communicate and thus, 'touch need not be technically sophisticated to prove strong medicine' (2005: 351).

This is by no means an exhaustive review of Classen's (or Rasmussen's) book and similarly The Book of Touch (2005) does not exhaust, or even make a dent in, the avenues open to the exploration of touch as a social practice. What the book does illustrate very well is that while touch can be thought of as a vivid site for enquiry, it is also very flexible. It seems to make more apparent the often arbitrary brackets or distinctions that we create around social phenomena. As such it offers up an interesting space in which to consider how experience as the being-ness of 'being in the field' and experience as perception and creation in the field flow into one another. In the next two sections of this paper I will discuss how touch can be incorporated as a kind of research practice and dwell on some of the ethical and theoretical issues that this brings up.

\section{Researcher as Toucher}

With theories of embodiment emerging in counterpoint to dualistic notions of the body and the closely related notions of objective observation, a new set of concerns come into being. I went into the field explicitly not wanting to reproduce a dualist notion of the body, hence my commitment to exploring the experiences of children in the oncology 
ward. However, while I carried this conviction into the methodological and theoretical sections of my research proposal, it remained glaringly absent in my ethical considerations.

Within anthropology, ethics is a serious bone of contention. Anthropologists have written at length about the problems inherent in codifying a set of ethics for research whilst simultaneously feeling the pressure to professionalize and safeguard the discipline at a time when academic enterprises are increasingly threatened by litigation and increasingly dependent on outside sources of funding (Caplan 2003). One of the major problems is that the codification of ethics confronts the anthropologist with the dilemma of how one retains a commitment to exploring the particular whilst adhering to a set of guidelines which cannot but reproduce some or other universalistic notion of morality. Furthermore, many of the debates around ethics speak to a much deeper question (some might say crisis) which confronts the discipline; the question of what or whom anthropology is for. These are serious questions and I cannot do justice to the complexity or sheer volume of the texts which have been written in response to them, but I will consider them briefly in light of my experiences around touch whilst conducting fieldwork.

At present, and since E.B Taylor's assertion that students 'go right forward, like a horse in blinkers' (Tylor 1885, cited in Stocking 1996: 370) un-swayed by political motivations, there is pressure on anthropologists' to embody particular values in their fieldwork conduct. Inherent in Taylor's assertion is the implication that fieldwork is good when it does not serve particular personal or political interests; when it is 'value-free' so to speak. Indeed, ethics themselves are often represented as 'value-free' divorced from any particular historical or geographical location (Caplan 2003). This relates back to the notion of objective knowledge espoused during the Enlightenment period, notions against which much of this paper has been speaking.

It is important to consider the ways in which such particular ideas about knowledge and knowledge or information 'gathering' become written into ethical rules and guidelines. An examination of almost any book on the ethics in social research reveals that ideas about what is ethical continue to be closely intertwined with ideas about the intrusive potential of research. There is often an accent on 'non-intrusive interview techniques' (Alderson and Morrow 2004: 52) and ethics tend to be largely concerned with guarding against the products of research subsequently and detrimentally re-entering the field, hence much attention is paid to the procedures that ensure confidentiality and anonymity (Alderson and Morrow 2004 43-6, 121, 138-9; Israel and Hay 2006: 4, 5, 34, 77-94, 96, 132-135, 140-141; Neuman 1997: 452). In addition to the many practical procedures recommended in books such as those listed above, attempts to curtail the intrusiveness of research are also explicitly and implicitly sought through the researchers' attempt to maintain their distance from the subject - to remain impartial, unbiased and fair. How does the view of the researcher as embodied and embedded in social worlds that are neither distinct from nor indifferent to those they study change the ways in which we think about ethics?

I was faced with this dilemma almost immediately upon entry into my fieldwork site. Although I was familiar with and in favour of calls for a subjective and bodily awareness in the field, I found myself ill-prepared for the large role that touch would come to play in my interactions with the children in the ward and how this would affect me, particularly with regard to the way I thought about my ethical responsibilities towards them. I became 
aware that I had in fact been holding onto a perception of myself as the detached observer and I became aware of this in the moment it became impossible to retain such a perception. I was created afresh with the gesture of taking a scared child's hand into my own.

In an interesting twist, this embodied experience, and the precedent it set for my future interactions with the children in the ward, can be read as both a departure from and a journey towards ethical research. On the one hand, I became conscious of how I had presented myself to those members of the hospital staff who had aided me in gaining access into the ward and how I was departing from this representation by becoming increasingly 'unprofessional' as I engaged in more and more cuddles. Furthermore, touching children is a highly regulated and politicised action; the only reference which I was able to find to touching children during research detailed one researcher's unease over her inability not to touch the children she worked with, despite being told by the schools who had granted her access that she was "not to engage in any type of physical contact with the children'1 (Holmes 1998: 26). This shows how my actions could have been read as a departure from ethical conduct.

However, the tactile demands placed on me by the children and the strong emotional connection that this created between us reconstituted my position in the field. Whereas before I had unconsciously positioned myself as the detached observer embodied as one who does not touch, the children's call for me to provide comfort through touch and my answering this call meant that I could no longer imagine or embody the 'unobtrusive', removed researcher. Instead, I become intimately involved at a physical, intellectual and (if we can still make distinctions) emotional level with the children and I came to embody a new kind of ethics.

This new embodied ethics opened the way for me to use empathy as the means by which I attempted to understand and share in the children's experiences and as a way to ensure that I recognised the children as ends in themselves, keeping my research objectives subservient to the needs and interests of the children. Anthropologists such as Michelle Rosaldo (1980) and later her husband, Renato Rosaldo (2004), have written convincingly on the ways in which emotions can be used in the production of ethnographic understanding. In a defence against concerns that emotivism leads to nothing but the expression of personal preferences, Lisette Josephides writes of fieldwork that ' $[i] \mathrm{n}$ so far as the reflexivity of 'being there' entails empathy as an emotional response, it is crucial to the moral person who... is created in the field' (2003: 61).

Moreover, touch gave me a way to answer one of the other questions anthropologists often struggle with; the question of who or what anthropology is for. I focused at length in the section above on the therapeutic benefits of touch and the reason for this was, firstly, because this was how many of the children described touch (equally salient, of course, were their vocalisations and demonstrations over how touch can be painful and invasive), and secondly, because the thought that I could help the children through touch was one I found deeply comforting. It validated my presence in the field and enabled me to honour the new ethical responsibilities that I felt towards the children; there was something I could actually do.

\footnotetext{
${ }^{1}$ This was seen by the school as a measure to safeguard against molestation and molestation accusations.
} 
In a piece titled Helping through Touch: the Embodiment of Caring, occupational therapist Suzanne Peloquin considers the 'use of empathetic touch because of its power and its ability to embody care' (1989: 299). She observes how in the English language sensory feeling is closely associated with emotional feeling. She asserts that touch is more than just a physical act but that it is 'an essential function of selves who are being, learning, embodied, and therefore feeling in the world' (1989: 303). This resonates with the notion of intersubjectivity, espoused by phenomenologists such as Merleau-Ponty, which maintains that it is through our senses that we not only perceive others but also share and create a world with them $(1968,1985)$. As Peloquin points out, touch diminishes the distance between people (1989: 304), so it can be used to engage our awareness of ourselves and others and the connection between us. Moreover, when touch is employed empathically, it can be used to 'communicate, to connect and comfort as a person, and to share the reality of [another's] world' (Peloquin 1989: 310).

Thus, the 'anthropologist as toucher' refers to the influence that we exert in the field. Rather than imagine that we can or should try to limit this influence, I suggest that we employ it as a tool for understanding the experiences of those we study and as a tool for exploring and satisfying our ethical responsibilities in the field.

\section{Researcher as 'Touched'}

Within anthropology, the idea of positionality often runs concurrently with a call for reflexivity. In addition to highlighting the avoidable subjectivity of the anthropologist, the reflexive movement corresponded with, and attempted to address, a growing awareness of the unequal power relations that tend to characterise the researcher/subject relationship (Clifford and Marcus 1986). Without negating or downplaying the validity of this concern, there is also a case to be made that anthropologists may often overestimate their influence over those they study and underestimate the influence that their research participants have over them.

Of all the senses, touch is extraordinary in that what is touched touches back. Above, I argued that engaging in physical contact with one's research subjects changes the dynamic between researcher and participant as well as what the researcher comes to know about those they are studying. Something that I only briefly mentioned, however, was the large extent to which this 'engagement in physical contact' was instigated by the research participants themselves.

The children I worked with were explicit regarding how they expected me to conduct myself during the research. Above all, it was expected and required that I take a sincere and heartfelt interest in them. Within the first few hours of my being in the ward, I was asked by a child to accompany him while he had a drip needle inserted into his hand and during the procedure we held hands. The children made it clear that my presence must benefit them. I was required to be available to provide comfort and support when they were in pain or distressed. I was also expected to entertain them and provide company. During my time in the ward, I was constantly being pulled, physically and verbally, into the children's spaces and clung to. I was required to be dependable, arriving when I had said I would and warning about any divergences from the routine we established. Moreover, conversations about when I would arrive at and leave the hospital frequently turned into negotiations; the children tended to want me to arrive earlier and stay later 
than I wanted to. These demands challenged the power dynamic between us, they meant that my time and conduct within the hospital turned into a negotiation of interests. I could ask questions, but not boring ones, and not when they would rather play.

Of course the agency or assertiveness that research participants can exercise in their encounters with anthropologists is context specific and so varies tremendously, but so too does the assertiveness and agency that the anthropologist can employ. I am of the persuasion that an embodied ethics which engages the empathetic sensibilities of the researcher can facilitate a more flexible negotiation of this relationship. From my perspective, the most significant demand which the children placed on me is that which I wrote about in the previous section - the demand that I be more than just academically interested in them. This demand opened up a relationship premised on mutual care and sharing. It also opened up the way for me to delve far more deeply into the concerns and desires of my informants than I imagine I would have been able had I not come to engage with them in this way. Thus, the researcher can be considered 'touched' both by the field and in the field through the demands that research, and research subjects, make as the sometimes opposing and sometimes supporting force in a contact relationship.

\section{Closing Remarks}

In the introduction to The Book of Touch, Classen remarks that 'the subject of touch, it seems to me, requires something different from such typical scholarly elucidation. Touch is better served by a rough and ready approach that acknowledges and grapples with the tangled, bumpy and sticky nature of the topic' (2005: 5). It seems that, despite some effort to the contrary, this paper supports this assertion. Touch works to collapse mind/body dichotomies in a way that academic writing does not yet seem able to cope with. However, in an attempt at a tidy ending, I would like to conclude by borrowing (as many others have before me) Mary Douglas's (1966) observation that some things are particularly 'good to think with', and close with the argument that touch is good to think with. As a relatively unexplored subject in the social sciences, it presents exciting opportunities for greater creativity and flexibility in the ways that we can position ourselves as embodied researchers and imagine our research sites.

\section{Acknowledgements}

This work was produced under the tutelage of the Social Anthropology Department at the University of Edinburgh in 2009. However, the research that drove it was conducted under the tutelage of the Department of Social Anthropology at the University of Cape Town. Special thanks goes to Dr Susan Levine who supervised this research. Her guidance and support has been invaluable

\section{About The Author}

In 2009 the author graduated with a Master Degree in Medical Anthropology from the University of Edinburgh. She is now enrolled in the Social Anthropology PhD programme at the University of Cape Town and is conducting research in a South African township looking at the lives of children affected by chronic illnesses. 


\section{Bibliography}

Alderson, P and Morrow, V. (2004), Ethics, Social Research and Consulting with Children and Young People, U.K: Barnardos.

Classen, C. (2005), The Book of Touch, Oxford: Berg.

Clifford, J. and Marcus, G. (1986), 'Introduction: Partial Truths' in Writing Culture: The Politics and Poetics of Ethnography, Berkeley: University of California Press.

Csordas, T. (1994), 'Introduction: The Body as Representation and Being-in-the-world', in T. Csordas (ed), Embodiment and Experience, Cambridge: Cambridge University Press.

Douglas, M. (1966), Purity and Danger: An Analysis of Concepts of Pollution and Taboo, London: Routledge and Kegan Paul.

Farquhar, J. and Lock, M. (2007), 'Introduction', in J. Farquhar, J. and M. Lock, Beyond the Body Proper: Reading the Anthropology of Material Life.

Halstead, N., Hirsch, E., and Okely, J. (2008), Knowing How to Know: Fieldwork and the Ethnographic Present, New York: Berhahn Books.

Holmes, R. (1998), Fieldwork with Children, London: Sage Publications.

Israel, M. and Hay, I. (2006), Research Ethics for Social Scientists, London: Sage Publications.

Jackson, M. (1995), At Home in the World, North Carolina: Duke University Press.

Kleinman, A. (1988), The Illness Narratives: Suffering, Healing, and the Human Condition, New York: Basic Books.

Lock, M. and Scheper-Hughes, N. (1987), 'The Mindful Body: A Prolegomenon to Future Work, in Medical Anthropology Quarterly (1): 6-41.

Merleau-Ponty, M. (1968), The Visible and the Invisible, Evanston, IL: Northwestern University Press

---- (1985), 'The Experience of Others', in Review of Existential Psychology and Psychiatry, XVIII: 33-72.

Neuman, L. (1997), Social Research Methods: Qualitative and Quantitative Approaches, Boston: Allyn and Bacon.

Okely, J. (2007), 'Embodying Fieldwork', in C. Shilling (ed), Embodying Sociology: Retrospect, Progress, and Prospects, Malden, MA: Blackwell Publishers. 
Peloguin, S (2005), 'Helping through Touch: the Embodiment of Caring', in Journal of Religion and Health, 28 (4): 299- 320.

Rasmussen, S. (2006), Those who Touch: Taureg Women in Anthropological Perspective, DeKalb: Northern Illinois University.

Rosaldo, M. (1980), Knowledge and Passion: Ilongot Notions of Self and Social Life, Cambridge: Cambridge University Press.

Rosaldo, R. (1993), Culture and Truth: The Remaking of Social Analysis, Boston: Beacon Press.

----- (2004), 'Grief and a Headhunter's Rage', in N. Scheper-Hughes and P. Bourgois (eds) Violence in War and Peace: an Anthology, Oxford: Blackwell Publishing.

Stoller, P. (1989), The Taste of Ethnographic Things: the Senses in Anthropology, Philadelphia: University of Pennsylvania Press.

Tuan, Y. (2005), 'The Pleasures of Touch', in C. Classen, (ed), The Book of Touch, London: Berg.

Thayer, S. (1982), 'Social Touching', in W. Schiff and E. Foulkes (eds), Tactual Perception, Cambridge: Cambridge University Press. 